Tesis. Año 12, 11(12), 13-30

\title{
Una aproximación a la música andina: el huaino, el harawi y el yaraví
}

\author{
Ynés Victoria Alcántara Silva \\ yneseud@gmail.com
}

\section{Resumen}

El presente trabajo es una aproximación a la música andina y estudia el especial significado que la música tiene para los pueblos del ande peruano. E1 artículo analiza el origen y evolución de los géneros musicales en el mundo andino, cuyos antecedentes se encuentran en la música prehispánica. Igualmente, el trabajo estudia el surgimiento, desarrollo y los temas de tres conocidos géneros de la música andina: el huaino, el harawi y el yaraví. De los tres géneros musicales, el huaino es el género más popular de la música andina; presenta variadas formas y se cultiva en todas las regiones del Perú. El harawi es un género de la música prehispánica que se ha conservado con determinadas características en los pueblos del interior del país. El yaraví es un género musical de carácter mestizo que surge a partir de la evolución que experimenta el harawi durante la época republicana y se caracteriza por expresar la tristeza del alma humana.

Palabras clave: música andina, géneros musicales andinos, huaino, harawi, yaraví.

\begin{abstract}
This work is an approach to the Andean music and it studies the special significance that music has for the people of the Peruvian Andes. The article analyzes the origin and evolution of music genres in the Andean world, whose background belongs to the pre-Hispanic music. Likewise, the work studies the emergence, development and themes of the three known genres of Andean music: huaino, harawi and yaravi. Of these three musical genres, the huaino is the most popular genre of the Andean music; it has varied forms and it is cultivated in all regions of Peru. The harawi is a genre of the prehispanic music that has been preserved with certain characteristics in the people of the countryside. The yaravi is a mestizo music genre that emerges from the evolution of the harawi during the Republican era and it is characterized by expressing the sadness of the human soul.
\end{abstract}

Keywords: Andean music, Andean music genres, huaino, harawi, yaravi. 


\section{Una aproximación a la música andina: el huaino, el harawi y el yaraví}

\section{Evolución de la música andina}

En los Comentarios reales de los Incas del Inca Garcilaso de la Vega (1609) y en Nueva Corónica y Buen Gobierno de Felipe Guamán Poma de Ayala (1616) se encuentra información de valor para el estudio del origen de la música andina y su evolución. En pasajes de estas crónicas, figura la mención de diversos géneros musicales prehispánicos, así como referencias a los instrumentos musicales que los antiguos peruanos utilizaron para sus composiciones y los temas que se cantaban.

Sobre las danzas en la época incaica, Guamán Poma dice: "La fiesta de los Ande Suyos desde el Cuzco hasta la montaña y la otra parte hacia la lamar [sic] del Norte es cierra. Cantan y dansan uarmi auca, anca uallo [danzas]" (2006, p. 296). De acuerdo con la Corónica, en los tiempos imperiales, el canto, la música y la danza estaban íntimamente relacionados, lo que se mantiene hasta el día de hoy. Los episodios referidos a la música, que se hallan narrados, así como representados en los dibujos de Guamán Poma, evidencian, por otro lado, el respeto que existía por las lenguas originarias, ya que los danzantes y cantantes cantaban sus creaciones en su propia lengua:

Cantan y baylan los Antis y Chunchos, dici así: "Caya caya, cayaya caya, caya caya, cayaya caya, cayaya caya". Al son de esto cantan y dansan y hablan lo que quiere en su lengua. Y responde las mugeres a este son: "Cayaya caya, cayaya caya", y uan tocando una flauta que llaman pipo (2006, p. 296 y p. 298).

Guamán Poma identifica diversos géneros musicales que se desarrollaron antes de la conquista española. Entre ellos, menciona los siguientes: haylli, arawi, qachwa, llamaya, pachaca, guanca, variacza, qawa y araui. Muchas de estas expresiones dancísticas y musicales se fueron perdiendo hasta desaparecer por completo durante los años de la conquista y la colonia. Las formas que sobrevivieron fueron variando con el tiempo. 
Garcilaso de la Vega, en el capítulo XXVI del Libro II de los Comentarios reales, brinda referencias sobre las ciencias numéricas y la música en el Imperio de los Incas. El cronista cuzqueño describe los instrumentos musicales hechos de cañuto: "[...] cuatro o cinco cañutos atados a la par. Cada cañuto tenía un punto más alto que el otro [...] como las cuatro voces naturales: triple, tenor contralto y contrabajo" (1991, T. I, p. 129). Sobre el contenido temático de la música en el Imperio Incaico, Garcilaso explica que eran "cantares, compuestos en versos medio, los cuales por la mayor parte eran de pasiones amorosas, - de placer, ya de pesar-, de favores o disfavores de la dama” (1991, T. I, p. 129).

Los estudios antropológicos y etnográficos han demostrado que los pueblos preíncas habían desarrollado culturas musicales sumamente complejas. Tal como lo explica Chalena Vásquez, con el adelanto tecnológico logrado, dichos pueblos llegaron a elaborar instrumentos musicales de diversos materiales: "arcilla, oro, plata, cobre, madera, caña, huesos, plumas, semillas, calabazas, etc." (2007, p. 8). Para alcanzar esta capacidad, desarrollaron conocimientos sobre la acústica y la armonía del sonido y del timbre. Vásquez explica que, con la venida de los españoles, llegaron los instrumentos de cuerda y "la escritura alfabética y musical", a la vez que se producía un impacto en la música: "[...] se incorporaron a la vez nuevas danzas, canciones, géneros musicales procedentes de las culturas europeas" (2007, p. 10). Bajo la influencia de estos cambios, también se dio la indigenización de los instrumentos musicales. Para Vásquez, este proceso se produjo porque en el Perú ya existía un conocimiento estético musical altamente desarrollado.

La música y la danza formaron parte de las diferentes actividades agrícolas, fiestas, ritos y ocasiones significativas del ciclo vital de la comunidad. La música acompañaba el ciclo anual de actividades: carnavales, cosecha, herranza, siembra, festividades religiosas, etc. Estaba presente, además, en una serie de ocasiones significativas del ciclo vital: cortapelo, matrimonio, techacasa, cumpleaños, muerte. Se hallaba íntimamente asociada a diferentes tipos de bailes, no solo huainos sino bailes colectivos como las pandillas, diabladas, negritos y otros con muchos elementos de la representación teatral.

En la época colonial, la religión intervino en el proceso de evangelización y extirpación de idolatrías, originando el cambio y evolución de la música. Para José María Arguedas, los antiguos clérigos fueron quienes fundaron la literatura quechua, y la música no dejó de estar presente en este proceso: "Afirmamos que el conjunto de himnos y oraciones y parábolas quechuas católicos pertenecen a la literatura quechua con tanta propiedad como los cantos y mitos folklóricos" (2012, T. 2, pp. 171-172).

Explicar el panorama evolutivo de la música andina resulta muy complejo, ya que la diversidad y la plasticidad son las principales características de esta. 
Sin embargo, podemos identificar dos grandes momentos históricos y sociales que desencadenaron la evolución de la música andina popular. Un primer momento fue la conquista y asimilación de la cultura occidental. Con la llegada de los españoles, muchos de los géneros musicales fueron desapareciendo y otros modificaron su estructura, contenido y ritmo; pero se mantuvieron la esencia y el sentimiento incaico. Un segundo momento social interno fue el proceso de urbanización y los grandes movimientos migratorios.

Raúl Romero explica este proceso evolutivo mediante dos criterios fundamentales para distinguir la música indígena tradicional de la música mestiza: $e l$ contexto y la estructura. La música indígena está asociada a contextos específicos en los que se desenvuelve el hombre del ande. Al respecto, Romero nos explica: "La música indígena está íntimamente ligada a contextos específicos, como por ejemplo los funerales, al matrimonio, al trabajo de la tierra y a determinadas ocasiones festivas" (2007, p. 231).

La interrelación de la música indígena con estos contextos ha hecho que su denominación, en la mayoría de los casos, reciba el nombre de la ocasión propicia. Algunos ejemplos, menciona Romero, son la música de la marcación del ganado, de los carnavales, de las faenas comunales. Esta difusión cerrada a espacios de convivencia de las comunidades indígenas ha hecho que la música indígena se presente como una oposición frente al mestizaje. Al mismo tiempo, a través de esta opción cultural, se expresa un deseo de continuidad o de resistencia frente a la cultura hegemónica.

En el otro margen, está la música mestiza, que presenta mayor grado de permeabilidad y adaptación a los cambios. El desligarse de su contexto para adquirir independencia propia ha hecho de la música mestiza la expresión popular de los pueblos andinos. El huaino, la muliza y el yaraví se desarrollan libres de los contextos tradicionales y adquieren nombre propio; esto hace que sean identificables y que puedan manifestarse en cualquier ocasión.

Sin embargo, no todas las expresiones musicales indígenas tradicionales “atraviesan por un proceso acelerado de transformaciones" (Romero, 2007, p. 233). Las expresiones musicales limitadas al ámbito comunal rural mantienen rasgos estructurales distintos de los de la música indígena tradicional popular. En estas expresiones indígenas tradicionales, se observa la "ausencia de la armonía occidental, que puede advertirse en numerosos casos de música instrumental y vocal” (Romero, 2007, p. 233).

La música mestiza continúa con su dinamismo expansivo y su posicionamiento de las distintas esferas sociales; predicciones estas hechas por Arguedas en sus diversos estudios sobre la música mestiza y su valor documental. De otro lado, las expresiones tradicionales indígenas que han resistido la influencia extranjera hoy se repliegan y buscan nuevos espacios para difundir su gran valor artístico y poético. 


\section{Clasificación de la música andina}

El primer estudio de la música andina es el trabajo La música incaica del músico Leandro Alviña (1909), para quien la música de los incas se caracterizaba por ser pobre y precaria frente al esplendor de los ritmos, sonidos, melodías e instrumentos musicales españoles. Así, el autor contrapone las expresiones musicales incaicas y españolas:

La conquista trajo juntamente [...] la civilización europea, la religión católica y con estas un sistema musical diferente del que se había conocido en el imperio. [...] varió las costumbres y la religión de los incas, transformó el desarrollo de nuestra música, sobre la que ejercieron influencia, no sólo el sistema nuevo diatónico y cromático, sino también el mismo género de música religiosa y profana, cada una de ellas con su respectiva tendencia, amén de la música vocal e instrumental no conocida en ésta bajo la forma de contrapunto y armonía sino tan solo con desarrollo homofónico y embrionario. La música profana subyugó a la nuestra con la arrogancia de sus marchas militares ejecutadas en bandas de guerra y de música, con sus sinfonías y fantasías, con sus romanzas, arias y coros, con sus cantatas, trovas, canciones y coplas, con sus peteneras malagueñas, soleares y seguidillas, boleros y jotas, zortzicos y otros, ya en forma de alboradas o dianas o en retretas y rondas y en ejecuciones de música de cámara (Cit. de Mendívil, 2014, p. 10).

Esta comparación hace vislumbrar un panorama sombrío para la música incaica frente al avasallamiento de la música occidental en el contexto de la conquista y la colonia. Alviña resalta características homofónicas y embrionarias como dos particularidades primitivas y limitantes de nuestra música. Su estudio propone, por primera vez, el uso de la escala pentatónica (cinco sonidos sin semitonos) en la música inca.

En 1925, los esposos Raoul y Marguerite D’Harcourt publican el libro La música de los Incas y sus supervivencias. En este estudio, se resalta la misma escala musical pentatónica — que años atrás Alviña ya había determinado-con algunas particularidades. Los esposos D'Harcourt explican este rasgo peculiar de la música incaica:

La escala empleada por los indios antes de la llegada de Pizarro, y que corresponde [...] a la revelada por un gran número de zampoñas y de flautas rectas antiguas, se compone de un conjunto de cinco sonidos en la octava, saltándose los semitonos de nuestra escala moderna; es decir: do, re, mi, sol, la, do (1990, p. 130).

Para los investigadores franceses, la característica de la escala pentatónica no fue una condición limitante para lograr la riqueza expresiva de las melodías incas; por el contrario, deja en claro que la música de los incas es rica, expresa 
fuerza, vitalidad; está llena de contornos, de espiritualidad, de un noble desprendimiento y está cargada de una melancolía nativa. Ambos estudiosos destacan el valor de la música inca y reclaman mayor atención e interés por ella:

Declaramos enfáticamente que existe un folklore musical andino, lleno de carácter y de vida, un folklore que constituye hoy en día la joya de toda América. Pero ¿quién lo conocía hace doce años? Los aires criollos publicados hasta entonces, las extrañas melodías declaradas indígenas no eran otra cosa que muestras insípidas de las canciones peruanas que llevaban claramente la marca de fórmulas europeas, al extremo que mucha gente bien informada creía que la voz de los quechuas había callado para siempre, ahogada por la influencia del viejo Continente (1990, p. XVIII).

Los citados músicos presentan un estudio detallado de las melodías y ritmos indígenas puros (monodias indígenas puras) y su diferenciación con las melodías mestizas. Estudios más recientes de Romero (2017), como el artículo "Panorama de los estudios sobre la música Andina en el Perú", que trata sobre las escalas musicales presentes en la música andina, evidencian que los incas no solo conocían la escala pentatónica como afirmaban las investigaciones de Alviño y D'Harcourt, sino que, por el contrario, coexistieron formas musicales muy variables. En sus indagaciones, Romero sigue la propuesta de Roel Josafat (1959) acerca de las "probables grandes formas musicales precolombinas" (2017, p. 86). En esta propuesta, se mencionan seis formas musicales que posiblemente correspondían a la época incaica, tal como se observa en el siguiente cuadro:

\begin{tabular}{|c|c|c|c|}
\hline & \multicolumn{2}{|c|}{ Probables grandes formas musicales precolombinas } & Ritmo \\
\hline \multirow{2}{*}{ A } & \multirow{2}{*}{$\begin{array}{l}\text { Básicamente TRI- } \\
\text { FÓNICO }\end{array}$} & $\begin{array}{l}\text { Hatun taki } \\
\text { Canto principal }\end{array}$ & Ritmo binario \\
\hline & & $\begin{array}{l}\text { Carnaval } \\
\text { Chanka }\end{array}$ & $\begin{array}{l}\text { Ritmo binario y } \\
\text { ternario }\end{array}$ \\
\hline \multirow[b]{2}{*}{ B } & \multirow{2}{*}{$\begin{array}{l}\text { Básicamente } \\
\text { PENTAFÓNICO }\end{array}$} & Wayno & $\begin{array}{l}\text { Ritmo ternario } \\
\text { Ritmo binario }\end{array}$ \\
\hline & & $\begin{array}{l}\text { Canto alternado de dos coros } \\
\text { con breve fórmula de respuesta } \\
\text { en cada frase }\end{array}$ & Ritmo binario \\
\hline \multirow{2}{*}{$\mathrm{C}$} & \multirow{2}{*}{$\begin{array}{l}\text { PENTAFÓNICO } \\
\text { y otros }\end{array}$} & Harawi & 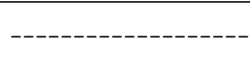 \\
\hline & & Wanka, canción ceremonial & ---------------- \\
\hline $\mathrm{D}$ & --- & $\begin{array}{l}\text { Sus formas musicales de } \\
\text { ritmos tonales surgen durante } \\
\text { el coloniaje }\end{array}$ & - \\
\hline $\mathrm{E}$ & -- & $\begin{array}{l}\text { Haylli, haycha canción de } \\
\text { trabajo }\end{array}$ & \\
\hline
\end{tabular}




\begin{tabular}{|l|l|l|l|}
\hline F & ----------------- & Wallina & ------------------- \\
\hline G & $\begin{array}{l}\text { Otros sistemas tona- } \\
\text { les y rítmicos }\end{array}$ & $\begin{array}{l}\text { Sus formas musicales surgen } \\
\text { durante la colonia }\end{array}$ & -------------------- \\
\hline
\end{tabular}

Adaptado de Roel Josafat. Tomado de Romero (2017, p. 86)

Un análisis panorámico de estas formas musicales nos permite observar que la música preínca fue la base para el cultivo de las diversas formas musicales que se desarrollaron durante la época colonial. La identidad y la defensa de nuestra cultura ancestral determinaron que algunos géneros musicales de la época precolombina aún subsistan. Por otro lado, el espíritu creativo del hombre del ande y el proceso de la transculturación durante el mestizaje, posibilitaron la bifurcación de los géneros musicales del incario, en otras formas musicales que tuvieron como germen la música inca.

Las formas musicales de la época del incanato estuvieron arraigadas en un contexto social que determinó su permanencia y desarrollo. La evidencia más directa de la relación entre la expresión musical y las actividades sociales de cada ayllu se encuentra documentada en Nueva Corónica y Buen Gobierno de Guamán Poma: "En estos huelgos que tienen cada ayllo y parcialidad deste rreyno no ay que dizelle nada ni se entremeta ningún jues a enquietalle a los pobres sus trauajos y fiesticillas y probesa que hazen cantar y baylar, comer entre ellos" (2006, p. 288). Cada ayllu realizaba sus fiestas y bailes a la usanza de su grupo social. Esta variedad en la interpretación y ejecución de sus bailes y música generó una gran diversidad de expresiones musicales durante la época incaica.

Para intentar una posible clasificación de los géneros musicales andinos, se debe tomar en cuenta el contexto de su creación y práctica y, sobre todo, los aspectos socioculturales de la región. Romero (2017) plantea esta necesidad en los términos siguientes:

La base de una clasificación adecuada de géneros musicales andinos debe recaer sobre el contexto sociocultural al cual pertenece la expresión musical, más que sobre factores exclusivamente formales. Esto se afirma no solo porque una clasificación debe apoyarse en criterios homogéneos y categorías similares, sino por las características de la música y sociedad andinas (2017, p. 87).

Los esposos D’Harcourt (1990) proponen una clasificación siguiendo este criterio sociocultural: géneros musicales relacionados con "[e]1 canto religioso, las lamentaciones funerarias, el canto amoroso, la canción, la danza cantada o instrumental, los cantos de despedida, la pastoral" (1990, p. 167). Los autores reconocen que su estudio tiene limitaciones en cuanto a la definición, caracterización y áreas regionales en las que estarían comprendidas dichas formas 
musicales. No obstante, reconocen el valor de la música andina por encima de las expresiones de otras culturas y pueblos amerindios.

Una propuesta más actual y completa sobre la clasificación de los géneros musicales andinos la encontramos en el "Esquema utilizado por el Instituto de Etnomusicología de la Pontificia Universidad Católica del Perú” (Romero, 2017, p. 87).

La música incaica, con sus variantes y matices, nos plantea un reto mayor para comprender y configurar el gran aporte cultural y musical de nuestros antepasados. Todas las expresiones musicales de los pueblos del ande transitan el pensamiento andino a través de diversas formas y géneros musicales. Su relación con los contextos socioculturales les otorga el arraigo y el espíritu identitario que debemos conocer para comprender mejor la cultura andina, su pensamiento, arte y filosofía.

\section{ESQUEMA DE CLASIFICACIÓN DE GÉNEROS Y FORMAS MUSICALES ANDINOS}

\begin{tabular}{|c|c|c|c|}
\hline $\begin{array}{l}\text { Universos } \\
\text { Musicales }\end{array}$ & $\begin{array}{l}\text { Géneros } \\
\text { Musicales }\end{array}$ & $\begin{array}{l}\text { Formas } \\
\text { Musicales } \\
\text { Asociadas }\end{array}$ & \\
\hline $\begin{array}{l}\text { Música del } \\
\text { ciclo vital }\end{array}$ & $\begin{array}{l}\text { Bautizo } \\
\text { Corte de pelo } \\
\text { Cortejo } \\
\text { Matrimonio } \\
\text { Funerales } \\
\text { - Velorio }\end{array}$ & Harawi & $\begin{array}{c}\text { Formas Musicales de } \\
\text { contexto libre } \\
\text { (Se asocian a diversos } \\
\text { contextos) }\end{array}$ \\
\hline $\begin{array}{l}\text { Música de } \\
\text { Trabajo }\end{array}$ & $\begin{array}{l}\text { Trabajo agrícola ( siembra, } \\
\text { cultivo, cosecha) } \\
\text { Trabajo ganadero (marca } \\
\text { del ganado) } \\
\text { Trabajo comunal } \\
\text { (construcción, limpia de } \\
\text { acequias) } \\
\text { Danzas - drama } \\
\text { Carnavales } \\
\text { Navidad } \\
\text { Año Nuevo } \\
\text { Ritos festivos (saludos, } \\
\text { marcha, corridas de } \\
\text { toros) }\end{array}$ & $\begin{array}{l}\text { Wifala; } \\
\text { Carnaval; } \\
\text { Pukllay; } \\
\text { Pumpin }\end{array}$ & $\begin{array}{l}\text { Huayno y sus } \\
\text { variantes regionales: } \\
\text {-chuscada (Ancash) } \\
\text {-pampeña (Arequipa) } \\
\text {-chimaycha } \\
\text { (Amazonas, Huánuco) } \\
\text {-cachua (Cajamarca) } \\
\text {-huayllacha (Valle del } \\
\text { Colca) } \\
\text { Yaraví } \\
\text { Muliza } \\
\text { Pasacalle } \\
\text { Marinera }\end{array}$ \\
\hline Música Religiosa & $\begin{array}{l}\text { Rezos } \\
\text { Salmos } \\
\text { Himnos } \\
\text { Procesión } \\
\text { Ofrendas rituales }\end{array}$ & $\begin{array}{l}\text { Villancicos; } \\
\text { Wakataki }\end{array}$ & \\
\hline
\end{tabular}

Tomado de Todas las músicas. Diversidad sonora y cultural en el Perú (Romero, 2017, p. 87) 


\section{E1 huaino y su clasificación}

La caracterización, la clasificación y la ubicación geográfica del origen y desarrollo del huaino han sido estudiados de forma muy detallada por Arguedas. En su artículo "La canción popular mestiza e india en el Perú. Su valor documental y poético", publicado en La Prensa de Buenos Aires en 1940, aborda la importancia del huaino como canción popular, colectiva y anónima de la cultura mestiza e india.

Arguedas relaciona este género musical con los elementos de la cosmovisión andina, apus (montañas), con la naturaleza y con cada uno de los indios, habitantes del Perú. A la vez, define el huaino como "[...] la huella clara y minuciosa que el pueblo mestizo ha ido dejando en el camino de salvación y de creación que ha seguido" (2012, T. 1, p. 277). Nuestro escritor aclara que, en sus inicios, el huaino fue anónimo y en sus versos se expresaban el corazón y los sentimientos colectivos de los pueblos. Por esa razón, el escritor y antropólogo centra su estudio en el cambio y evolución que se observa en este género musical. Al respecto, sostiene: "[...] hay algo que es fundamental: la música del wayno ha sido poco alterada, mientras que la letra ha evolucionado con rapidez $\mathrm{y}$ ha tomado formas infinitamente diversas, casi una forma para cada hombre" (2012, T. 1, p. 277).

Arguedas encuentra en el huaino el género musical capaz de mantener su pureza musical, la resistencia para mantener los rasgos melódicos; y, a la vez, su capacidad para asimilar los cambios en el contenido, sin trastocar su pureza melódica. Atribuye estas mismas características a sus autores indios y mestizos: "El indio y el mestizo de hoy, como el de hace cien años, siguen encontrando en esta música la expresión entera de su espíritu y de todas sus emociones" (2012, T. 1, p. 277).

Con el mestizo, se desarrolla el huaino popular y, al mismo tiempo, se revelan los nombres de los propios autores. Sobre este aspecto, Arguedas afirma: "Es interesante comprobar cómo en el centro del Perú es donde aparece primero el canto mestizo con firma y de autor conocido" (2012, T. 1, p. 279). Existen factores por los cuales en otras regiones del Perú (el sur) el huaino de autor conocido aparece muy tardíamente (veinte años después que en el centro). Una de estas causas es la diferencia del ritmo con que se desarrolla el proceso de mestizaje. En ese sentido, cabe señalar que la actividad económica (comercio y minería) es el factor determinante que precipita el proceso de mestizaje en los pueblos del ande peruano.

Al igual que Arguedas, Carlos Huamán (2006), en su libro Atuqkunapa Pachan. Estación de zorros, identifica el mismo ámbito geográfico como área de origen y desarrollo del huaino. La región cultural de Pokra-Chanka-Apurímac, 
Ayacucho y Huancavelica es la zona geográfica donde se llevó a cabo el mayor proceso de evolución y desarrollo del huaino. Varios de los rasgos señalados por Arguedas siguen vigentes en la actualidad de acuerdo con el estudio de Huamán. La expresión cultural Pokra-Chanka continúa reproduciendo sus manifestaciones artístico-musicales, sus prácticas religiosas y parte de su organización social; por lo que dicho legado sigue vigente.

De todas las expresiones musicales mestizas tradicionales populares, el huaino es el que ha tenido un doble desarrollo. Este género musical ha resistido al cambio expandiéndose hacia áreas rurales de menor contacto con la urbe. Pero, al mismo tiempo, la población andina mestiza ha tomado sus rasgos esenciales para reelaborarlas de acuerdo con los nuevos contextos del mestizo migrante. Sobre este punto, Romero sostiene: "Este fenómeno se puede observar en el caso del surgimiento del huayno, a expensas del despliegue de la kashwa y del desarrollo del yaraví sobre las raíces del harawi campesino, durante los siglos de dominación colonial" (2007, p. 243).

A principios del siglo XX y con el auge del universo mestizo y del capitalismo, se desarrolla un impacto en la música andina: expresiones musicales como el waylarsh de cosecha se transforman en un género libre y autónomo. Por otro lado, los instrumentos indígenas son asimilados por los pueblos mestizos, quienes llevaron esta expresión musical a la capital de la provincia. Hoy en día, el huaino es la "expresión más difundida y de mayor arraigo en el Perú andino mestizo" (Romero, 2007, p. 243). Su variedad en el estilo permite identificar su carácter regional, así como también el estrato social al que pertenecen sus cultores.

Para Vásquez, el huaino es el género musical más popular en el Perú, cantado y bailado en todo tipo de ocasiones (fiestas) en cualquier época del año y tocado por diversidad de instrumentos musicales. Para la estudiosa de la música andina, son variados los estilos del huaino:

Adquiere muy distintos estilos de acuerdo a la región, a los sectores sociales, a zonas rurales y zonas urbanas. Se canta en varios idiomas: castellano, quechua, aymara, etc. Según las regiones, adopta el nombre de "cholada", "pampeña", "chuscada", "serranita", etc. Las formas de acompañamiento, las velocidades, los timbres y balanceos sonoros perfilan identidades culturales distintas (2007, p. 28).

Vásquez propone una clasificación que responde al estilo del huaino, que puede variar de acuerdo con el contexto, espacio geográfico y social. A su vez, el género adoptará diversos nombres de acuerdo con la región en que se desarrolle. De todos los géneros musicales, el huaino es el que mejor se ha adecuado a los nuevos ritmos y melodías. Su interpretación responde a diversos contextos y estados de ánimo; por ello, ha sido mejor recepcionado por los mestizos. 
Otras clasificaciones se hallan recogidas por Huamán en su mencionado libro. El investigador considera dos clasificaciones que comparten similitudes. Una primera clasificación responde al tema, el ritmo y el lenguaje, en el que confluyen una mistura de expresiones: de amor, alegría y tristeza. En esta mistura existen, a su vez, subdivisiones, "pues se emplea como un canto lírico, épico satírico y picaresco" (20076, p. 35). De este modo, encontraremos huainos sentimentales, alegres, con un lenguaje de amor, un lenguaje picaresco al que se suma un ritmo alegre y vertiginoso.

Una segunda clasificación responde a cuatro vertientes: huainos sentimentales, sociales, satíricos y políticos. Esta división no responde a un espacio geográfico determinado, pero sí a una intención metodológica. Para Huamán, la entonación del intérprete del huaino es lo que le otorga la plasticidad rítmica que posibilita transitar "del tono lírico al épico o dramático, o viceversa" (2006, p. 36). Esta característica, igualmente, le permite ser interpretado en diversos contextos y expresar variados sentimientos.

\section{El harawi}

El harawi es un género lírico y musical que ha tenido mayor arraigo en las prácticas socioculturales de los antiguos peruanos y lo sigue teniendo actualmente. Para referirnos a este género musical, se emplean algunas variantes ortográficas. El Diccionario etimológico de palabras del Perú de Julio Calvo Pérez las menciona en la explicación de la entrada "haravico". Al analizar la etimología de este último término, el autor señala lo siguiente: "Voces primitivas, pero dignas de menor consideración léxica en el uso son, entre otras, sin que varíe ni el significado ni la etimología: harahui, jarahui, y harawi” (2014, p. 346).

Las primeras evidencias de la presencia del harawi en la literatura oral y cultura musical incaica datan de la época de la colonia. Guamán Poma menciona en pasajes de su Nueva Corónica testimonios de cantos, bailes y danzas de los pueblos del antiguo Perú: "Canciones y múcicas del Ynga y de los demás señores deste rreyno y de los yndios llamado haraui [canción de amor] y uanca [canción], pingollo [flauta], quena quena [danza aymara]" (2006, p. 288). En los pasajes en los que representa las celebraciones o fiestas del inca, el cronista relata cómo se emiten con regocijo y entusiasmo los cantos (harawis) en los que participan hombres y mujeres por turnos. A través de dichas referencias, se afirma la existencia del harawi.

El cronista documenta escenas sobre bailes y formas musicales en el contexto de la vida incaica:

Con conpás muy poco a poco, media ora dize: "Y, y, y", al tono del carnero. Comiensa el Ynga como carnero; dize y está diziendo "yn". 
Lleua ese tono y dallí comensando, ua disiendo sus coplas muy muchas. Responde las coyas [reina] y ñustas [princesa]. Cantan a bos alta muy suuauemente. Y uaricsa y araui dize ací: Araui araui aray araui yau araui." Uan deciendo lo que quieren y todos al tono de araui. Responden las mujeres: "Uaricsa ayay uaricza chamay uaricza, ayay uaricza." Todos uan deste tono y las mugeres rresponden. (2006, p. 293).

De esta manera, el autor pone de relieve las escenas de fiesta y celebración que realizaban los representantes de la nobleza inca. Todos celebran al tono de harawi y son las mujeres quienes responden con voz aguda. Al respecto, es importante citar a Arguedas sobre las particularidades del harawi: "No lo entonan los hombres, sólo las mujeres, y siempre en coro, durante las despedidas o la recepción de las personas muy amadas o muy importantes [...] La voz de las mujeres alcanza notas agudas imposible para las masculinas" (2012, T. IV, p. 362). Esta particularidad en la voz de las mujeres permite otorgarles el rol principal en la interpretación de los harawis por su voz alta y aguda.

Mientras Guamán Poma nos describe pasajes de las celebraciones incas, Garcilaso (1609), en el capítulo XXVII del Libro II de Comentarios reales, que trata sobre la geometría, aritmética y música de los Incas, brinda referencias que nos permiten explicar la relación entre el araui y el término harávec. La palabra harávec se suscribe, según Garcilaso, a un contexto lírico de origen, de creación poética. Dicho término también se asocia a la palabra harauicus (poetas). De acuerdo con el cronista, se trata de los poetas incas, que son los creadores, los "inventores" de los versos que acompañan a la música y la danza del harawi (1991, Cf. T. I, pp. 130-131).

Un primer rastreo etimológico del término harawi lo tenemos en el Vocabulario de la lengua general de todo el Perú llamada lengua qquichua o Inca de Diego González Holguín publicado en 1608. En él, encontramos la definición de la palabra haraui asociada a los "Cantares de hechos de otros o memoria de los amados ausentes y de amor y afición y agora se ha recibido por cantares deuotos y espirituales" (1989, p. 152). Para la época de la publicación del Vocabulario de González Holguín, inicios del siglo XVII, se pone de relieve el carácter triste y melancólico del harawi colonial. Esta característica plañidera y triste del harawi será tomada en cuenta por Raúl Porras Barrenechea al desarrollar su detallada historia sobre el yaraví.

Estudiosos como Porras Barrenechea (1946), Arguedas (1957), Jesús Lara (1980), José Varallanos (1989) y Romero (2007) coinciden en afirmar que el harawi incaico o imperial es la expresión musical más popular en la sociedad inca. Este género poético y musical estaba ligado a diversos contextos y prácticas socioculturales como el trabajo agrícola, el cortejo, el matrimonio, los funerales, etc. Cabe precisar que estos espacios vinculados con la expresión lírica 
del harawi no necesariamente eran de carácter triste y lastimero como algunos autores lo han señalado. Así, Varrallanos dice: "[...] con el harahui no solamente se cantaban los motivos placenteros o tristes del hogar, sino se le entonaba también en coro, colectivamente, como manifestación de alabanza a la naturaleza y de la alegría en la realización de las faenas agrícolas [...]" (1989, p. 34).

De acuerdo con los aportes de los estudiosos de la música incaica, se puede afirmar que el harawi es la mayor expresión lírica y musical de la época precolombina y se convierte en el germen de la formación de nuevos géneros líricos y musicales como, por ejemplo, el yaraví mestizo y colonial.

La creación poética del harawi durante la época del incanato era desbordante y constituyó el único género lírico y musical que presentó una clasificación particular para cada contexto y sentimientos que expresaba. Al respecto, Guamán Poma registra algunos ejemplos de los versos que forman parte de esta clasificación. En esa línea, es conveniente citar a Lara, quien, al explicar las clases de harawi, sostiene: "Tomaba diversas denominaciones de acuerdo al sentimiento que le inspiraba. Jaray arawi, era la canción del amor doliente; sank'ay arawi, la de la expiación; kusi arawi, súmaj arawi, warijsa arawi, las de la alegría, la belleza, la gracia, etc.” (1980, p. 44). Veamos algunos ejemplos:

\section{Jaray arawi}

Sijllallay, chinchirkuma

Kajtiykicha

Umallaypi, sunqorurullaypi

Apaykachaykiman

\section{Jaray arawi}

Sajra auqachu, quya

Atiwánchij, llasawánchij,

$\mathrm{Ma}$, qoya, ujlla wañusun

\section{Sanka'y arawi}

Yaya kachapúrij,

Qillqa ápaj sh'aski,

Púrij simillayta,

Sunqollayta

Apapulláway

Yayallayman

Mamallayman

Willapulláway.

\section{Warijsa arawi}

¿T'ikayujchu chajrayki?

T’ikay tunpalla samúsaj
Si fueras flor de chinchercoma,

Hermosa mia,

En mi sien y en el vaso de mi corazón

Tellevaría

¿Qué enemigo maligno, reina,

Nos aniquila y nos sojuzga?

No en uno todos, reina, moriremos.

Padre mensajero,

Conductor de nuevas,

Haz que lleguen a mi padre

Y a mi madre

La tristeza errante

De mi acento

$Y$ la angustia

De mi corazón

$\grave{¿}$ Hay flores en tu sementera?

¿Vendré con el pretexto de las flores! 
Dicen los hombres y después una mujer exclama:

$$
\begin{array}{ll}
\text { ¡A Ajailli, chaymi palla! } & \text { ¡Hurra, sí, ésa es la dama! } \\
\text { ¡Ajailli, patallanpi! } & \text { ¡Hurra, abi está en el borde! } \\
\text { ¡Ajailli, chaimi ñust'a! } & \text { ¡Hurra, sí ésa es la infanta! } \\
& \text { (Lara, 1980, pp. 44-46). }
\end{array}
$$

La narrativa de Arguedas ilustra la versatilidad del harawi y su ejecución en diversos contextos específicos. Por ejemplo, podemos apreciar las piezas líricas de los harawis entonados por las mujeres para despedir a Antolín en Diamantes y pedernales. Del mismo modo, en Yawar fiesta, se cantan harawis para despedir a los varayok's que salen de Puquio, luego de terminar la construcción de la carretera. Estas formas líricas y musicales revelan puntos de dramatismo y de inflexión en el hilo narrativo por la emotividad y sentimiento que transmiten los cantos expresados por las mujeres.

\section{El yaraví}

El yaraví es un género poético y musical mestizo que despertó un debate e interés sobre su origen, evolución y difusión. Estudiosos de la literatura peruana como Luis Alberto Sánchez (1928), Porras Barrenechea (1946) y Antonio Cornejo Polar (1982) formulan puntos de vista para dilucidar el origen y desarrollo del yaraví como forma lírica y musical.

Hacia 1928, Sánchez señalaba que los arabicus o haravec eran los poetas creadores de los yaravíes, a quienes les atribuye características de rebeldía, inconformidad, sensibilidad a través de la cual buscan expresar con libertad sus amores o dolencias terrenales. Sánchez nos brinda la siguiente explicación: "E1 arabicus, o haravec (o "yaravista"), encarnaba la rebeldía estética, la sensibilidad inconforme, el hombre de espíritu libre aunque controlado en sus actos externos, el creador. Rapsoda y poeta, exégeta y creador, he aquí los términos perentorios de la vida literaria inca" (1981, T. I, p. 119).

Del mismo modo, Porras Barrenechea indaga sobre el origen del yaraví y no deja de lado las discusiones sobre la derivación de la palabra. Por ello, contrasta el origen primitivo del nombre yaraví con términos como aravi o haravi; nombres primitivos e incaicos hallados en los pasajes de las crónicas mestizas e indígenas. Encuentra la referencia más exacta en los Vocabularios y Diccionarios publicados por los frailes catequistas y estudiosos de la lengua quechua (González Holguín, Torres Rubio y José de Rodríguez). Estas indagaciones etimológicas y filológicas le permiten llegar a la conclusión de que el yaraví transita de una definición amplia en el siglo XVI a la singularidad de tono melancólico y monocorde del siglo XVIII. 
Porras Barrenechea encontraba que, efectivamente, existe un germen primitivo que se ha amalgamado con el alma de la canción incaica. Esta ha transformado y trastocado su sentido alegre, festivo y melancólico de la canción inca, con un aire sentimental, triste y plañidero. De este modo, el aravi se transforma en el yaraví durante la conquista, pierde su sentido colectivo, su carácter festivo y danzario del taqui y solo persiste el solitario gemido de las quenas. En esta transformación, no solo muta el nombre de la forma lírica y musical, sino, también, existe un cambio en el ánimo y espíritu de los poetas populares que le imprimen el tono triste y nostálgico por naturaleza.

Motivado por sus inquietudes sobre el origen del yaraví, Porras Barrenechea propone una posible biografía en sus "Notas para una biografía del yaraví" publicado en El Comercio el 28 de julio de 1946 (1999). El historiador de la literatura peruana distingue tres momentos en dicha biografía: un primer momento de los yaravíes lo identifica en la obra dramática Ollantay (publicada en 1780); en un segundo momento, ubica el debate sobre las particularidades del yaraví publicado por la Sociedad Amantes del País en 1791 en el bisemanario científico-literario Mercurio Peruano; y el último momento corresponde a los yaravíes compuestos por el poeta Mariano Melgar (1831).

Del mismo modo, Sánchez encuentra en las vertientes incas el origen del yaraví. Por ello, es determinante al afirmar que el yaraví ha evolucionado y ha pasado de un yaraví serrano, mestizo o cholo a un tipo de yaraví criollo y triste: "Del haravec quechua se evoluciona, paulatinamente al yaraví serrano, mestizo o cholo, y de ahí al "triste” criollo, costeño" (1981, T. I, p. 130). Por otro lado, Cornejo Polar (1981) reconoce que el yaraví proviene de una "matriz indígena prehispánica”; por tal motivo, en él subyace la revalorización de la tradición poética nativa.

En el drama Ollantay, publicado en 1780, se encuentran los primeros versos de la canción lírica del yaraví lastimero y triste. Dicho drama se convierte en el primer texto literario que incluye entre sus actos cantos, atribuidos por su autor, con el nombre de yaraví. Específicamente, en las escenas V y IX, se citan los versos del yaraví. Tomamos el yaraví del drama Ollantay, traducido del quechua al castellano por el quechuista J.M.B. Farfán (Cit. de Varallanos, 1989, p. 75):

Iskay munakow urpi

Llakin, phutin, anchhin, waqan

Aqorakis awqan toaqan

Huk siphi, qhwasi qhoqorpi

Hulnin kaqsi chinkachispa

Cayllukuzqan pitullanta

Qanparmanasqa, llakisqa

Kuk kap urpitaqui llakin

Pitullanta qhawarispa
Una pareja de amantes palomas

Se apena, abate, suspira, llora

La adversidad los separa

En soledoso y obscuro desierto.

A su pareja adorada

Una de ellas perdió

Allá entre roquedales,

Toda apenada y triste.

La otra paloma se afije. 
Wanñusqataña tarispa

Kay simpi, parqaq takin:

"Maymi, urpi, chayñawiyki

Chay chasqqoki munay-munay

Chay sunqoykiñukchunay

Chay achanqaray simiykinay".
A su compañera contemplando

Esta endecha ella entona;

¿Dónde están esos tus ojos, paloma

Ese tu amantísimo pecho,

Ese tu corazón de mis gozos,

Esos tus labios achanqaray?

En el año 1791, la Sociedad Amantes del País publica en las páginas del Mercurio peruano (22 de diciembre) el debate sobre las particularidades del yaraví. En este debate, participan dos jóvenes entendidos en las bellas artes. Con los seudónimos de Sicramio, y Leucipo y Eurifilo, exponen sus ideas sobre la música y, en particular, acerca del yaraví. Sicramio determina las características del yaraví de la época de este modo: "[...] los versos ya se refieren á alguna crueldad, ya á la funesta memoria de un objeto amado, ya al olvido injusto de un amante, ya á la desesperación de una imaginación zelosa, y ya á las tiranías del amor" (1964, T. III, Fol. 286). Sicramio describe el yaraví del siglo XVIII como triste, melancólico, capaz de penetrar el alma y sensibilizar el corazón más empedernido. Lejos está el carácter alegre y festivo de su antecedente, el harawi incaico.

E1 poeta Mariano Melgar y sus yaravíes constituyen el tercer momento en la biografía que desarrolla Porras Barrenechea. Este encuentra similitudes entre el yaraví de Ollantay y los yaravíes de Melgar:

El símil de las avecillas amorosas y tiernas con el corazón amante se asocia bien a la índole ingenua del yaraví y persistirá más tarde en Melgar y en mejores cultivadores del género. [...] Así queda definida desde el primer momento la índole del yaraví mestizo, octosílabo castellano, nostalgia sentimental, ingenuidad lírica [...] capaz de enternecer hasta el llanto (1999, p. 28).

El yaraví no solo expresa tristeza, suspiro y dolor, sino también, el alma y el sentimiento del pueblo indígena. Al ser una expresión musical tradicional popular mestiza, no se desvincula de su esencia nativa; guarda relación con la pena de amor, con la naturaleza, con el sentimiento del hombre del ande; conserva sus manifestaciones mestizas e incaicas.

Un panorama más actual sobre el estudio del yaraví lo encontramos en los estudios de Romero, quien clasifica al yaraví como música andina tradicional popular, ya que su creación y acogida se ha extendido por todas las regiones de nuestro país. La principal característica que determina su paso de lo tradicional a lo popular es su desapego a contextos específicos - cosecha, herranza, marcación del ganado- $-\mathrm{y}$ su adquisición de una definición propia de nombre "yaraví". Romero afirma que el yaraví, a inicios del siglo XX, conservaba aún sus rasgos de expresión colonial. De esta forma, logra ser popular entre la clase 
media cusqueña y de sus reuniones sociales. A diferencia del aravi incario, el yaraví mestizo es acompañado por instrumentos occidentales que incorporaron su melodía al acompañamiento de los versos tristes y melancólicos. Así lo documenta Romero: "El yaraví constituía un momento obligado en las reuniones sociales cuzqueñas siendo acompañado con piano, con guitarra o con conjuntos instrumentales de quenas, violines y mandolinas" (2007, p. 245).

Romero aclara que, en estas fiestas, se tenía preferencia por el huaino y la marinera como géneros bailables y que el paréntesis en la reunión, estaba reservado para el yaraví que se escuchaba con atención. Para Romero, el yaraví y el huaino logran integrarse en una única estructura. A modo de fusión, el yaraví y el huaino reconfiguran una nueva estructura que le otorga al yaraví su carácter festivo. Romero precisa lo siguiente: "Es justamente en este contexto que empieza a agregarse una "fuga" al yaraví — una sección final de movimientos más rápidos que generalmente era un huayno- - y que restituía el carácter festivo a la congregación social" (2007, p. 246).

El yaraví se ha expandido por todas las regiones del Perú; por ello, se configura como la expresión lírica y musical que forma parte de nuestro folclor y de nuestra literatura. Su configuración, sea el aravi incario o el yaraví mestizo, mantiene la esencia creativa y versátil de los pueblos del ande; connota las relaciones de sentimiento, melancolía, identidad y lucha tenaz para mantener el alma del pueblo andino. Como expresión literaria, el yaraví constituye el género lírico que simboliza y expresa el pensamiento y el sentir de los pueblos del Perú. Su origen y su resistencia han conservado rasgos andinos que han hecho que muchos críticos y estudiosos lo cataloguen como la máxima expresión del indio desposeído, de clase servil, desamparada.

\section{Referencias}

Arguedas, J. M. (2012). Obra antropológica. 7 t. Lima, Perú: Horizonte.

Arguedas, J. M. (1983). Obra completa. 5 t. Lima, Perú: Horizonte.

Calvo Pérez, J. (2014). Diccionario etimológico de palabras del Perú. Lima, Perú: Editorial Universitaria de la Universidad Ricardo Palma.

Casas Roque, L. (1985). El qarawi y su función social. Allpanchis, 25, 233-270.

Cornejo Polar, A. (1982). Sobre literatura y crítica latinoamericanas. Caracas, Venezuela: Universidad Central de Venezuela.

D'Harcourt, R. y M. (1990 [1925]). La música de los Incas y sus supervivencias. Lima, Perú: OXI.

Garcilaso de la Vega, Inca (1991). Comentarios reales de los Incas. 2 t. Edición de Carlos Aranibar. Lima, Perú: Fondo de Cultura Económica. 
Guamán Poma de Ayala, F. (2006). El Primer Nueva Corónica y Buen Gobierno. 2a ed. Edición de John Murra y Rolena Adorno. México D.F., México: Siglo veintiuno.

González Holguín, D. (1989). Vocabvlario de la lengra general de todo el Perv llamada lengua Qquichua o del inca. 2a ed. Lima, Perú: Universidad Nacional Mayor de San Marcos.

Huamán, C. (2015). Urpischallay. Transfiguraciones poéticas, memoria y cultura andina en el wayno. Lima, Perú: Altazor.

-. (2006). Atuqkunapa pachan. Estación de los zorros. Aproximaciones a la cosmovisión quechua-andina a través del buayno. Lima, Perú: Altazor.

-. (2004). Puente sobre el mundo Narrativa Memoria y Símbolo en la obra de José María Arguedas. México D.F., México: El Colegio de México.

Lara, J. (1980). La literatura de los quechuas. Ensayo y antología. 3a ed. La Paz, Bolivia: Librería y Editorial Juventud.

Martínez, M. (2002). La música como existencia real: Conversación con Celso Garrido Lecca. Lienzo, 23, 87-105.

Mendívil, J. (2014). Noticias del imperio: la visión trágica de la historia en la musicología temprana sobre la región andina y la canonización de la música incaica. Boletin Música, 37, 3-26.

Montoya, R. et al., Comps. (1997). Urqununapa yawarnin. La sangre de los cerros. 5 t. $2^{\mathrm{a}}$ ed. Lima, Perú: Editorial Universitaria.

Porras Barrenechea, R. (1999). Indagaciones Peruanas. El legado quechua. Lima, Perú: Fondo Editorial de la Universidad Nacional Mayor de San Marcos.

Romero Cevallos, R. (2017). Todas las músicas. Diversidad sonora y cultural en el Perú. Lima, Perú: Instituto de Etnomusicología de la Pontificia Universidad Católica del Perú.

Romero Cevallos, R. (2007). La música en el Perú. $2^{\mathrm{a}}$ ed. Lima, Perú: Fondo Editorial Filarmonía.

Romero Cevallos, R. (1993). Múisica, danzas y máscaras en los Andes. Lima, Perú: Fondo Editorial de la Pontificia Universidad Católica del Perú.

Sociedad Amantes del País (1964-1966 [1791-1795]). Mercurio Peruano. 12 t. Edición facsimilar. Lima, Perú: Biblioteca Nacional del Perú.

Varallanos J. (1989). El harabui y el yaraví. Dos canciones populares peruanas. Lima, Perú: Consejo Nacional de Ciencia y Tecnología.

Vásquez, C. (2007). Historia de la música en el Perú. $2^{\circ}$ fascículo de Educación para el Arte. Lima, Perú: Ministerio de Educación. 